\title{
LAZER E TURISMO NA REPRESA BILLINGS: ESTUDO DO PERFIL DOS USUÁRIOS NA PRAINHA DO RIACHO GRANDE EM SÃO BERNARDO DO CAMPO (SP)
}

\author{
Daniela Ferreira Amorim ${ }^{1}$
}

Danielli Cristina Granado ${ }^{2}$

\section{RESUMO}

Este estudo tem como objetivos discutir os usos da Represa Billings lazer, recreação e turismo. Pretende também conhecer o perfil dos usuários da prainha do Riacho Grande, localizada nesta Represa. Deste modo, foi realizado levantamento bibliográfico em obras e periódicos científicos e em documentos, disponibilizados pela Prefeitura Municipal de São Bernardo do Campo e notícias de jornais arquivadas no memorial e acervo da Cidade. Para analisar o perfil dos frequentadores da prainha foram realizadas entrevistas com 100 indivíduos escolhidos aleatoriamente, durante finais de semana de julho, agosto e setembro de 2012. A mudança na paisagem pela formação da Billings propiciou sua utilização para fins de lazer e recreação. Na prainha do Riacho Grande em São Bernardo do Campo, notícias do fluxo de turistas datam da década de 1970. A entrevista com os frequentadores da prainha demonstrou que a maioria era jovem, com renda de 1 a 2 salários mínimos e grau de escolaridade até o ensino médio. Oriundos da região metropolitana de São Paulo, sendo as cidades do $A B C$, as principais emissoras. A maioria visita o local acompanhado da família ou amigos, sempre aos finais de semana, para contemplar a paisagem. Ainda que suas águas não permitam o uso para recreação de contato primário, devido aos conflitos de usos existentes, os resultados obtidos corroboram com outros estudos realizados com frequentadores de "prainhas" no Brasil, demonstrando a importância desses locais como espaços de lazer destinados às populações urbanas do entorno, assim como para a promoção do turismo como alternativa de desenvolvimento local e regional.

PALAVRAS-CHAVE: Lazer, Recreação, turismo, Represa.

\footnotetext{
${ }_{1}^{1}$ Graduada em Turismo pela Univ. Estadual Paulista - UNESP.dani_fa@terra.com.br

${ }^{2}$ Bióloga, Doutora em Ciências da Eng. Ambiental pela EESC/USP, Professora da Univ. Estadual Paulista - UNESP. danielli@rosana.unesp.br
} 


\title{
LEISURE AND TOURISM AT BILLINGS DAM: STUDY OF THE GOERS PROFILE OF THE PRAINHA IN RIACHO GRANDE, SÃO BERNARDO DO CAMPO - SP
}

\begin{abstract}
This study aimed to discuss the uses of Billings Dam to leisure, recreation and tourism. Also want to know the profile of the Prainha do Riacho Grande goers, located in this dam. Therewith, was conducted the literature survey in scientific books and periodicals and documents provided by the Town of São Bernardo do Campo and news from newspaper archives of the City Memorial and Collection. For to analyze the profile of the Prainha goers was held interviews with 100 individuals randomly chosen, during the weekends of July, August and September 2012. The change in the landscape due to the formation of Billings has provided its use for leisure and recreation. At Prainha of Riacho Grande in São Bernardo do Campo, data about the tourist flows dating from the 1970s. The interview with Prainha goers showed that the majority was young (29-39 age), with incomes 1-2 minimum salaries and High School education level. Arising from São Paulo Metropolitan Region, mainly from the cities of $A B C$ region. The most respondents, declared to visit the place frequently, with family or friends, always on weekends, to contemplate the landscape and enjoy the products marketed there. The results corroborates with other studies of "prainhas" goers in Brazil, demonstrating the importance of these places as recreational spaces to urban population surroundings, as well as for the promotion of tourism as an alternative for local and regional development.
\end{abstract}

KEY-WORDS: leisure, recreation, tourism, dam.

\section{OCIO Y TURISMO EN LA REPRESA BILLINGS: ESTUDIO DE LOS USUARIOS DE LA PRAINHA DE RIACHO GRANDE, SÃO BERNARDO DO CAMPO - SP}

\begin{abstract}
RESUMEN
Este trabajo tiene como objetivo analizar los múltiples usos de la represa Billings para ocio y recreación. También quiere conocer el perfil de los usuarios de la Prainha de Riacho Grande, ubicado en esta represa. Por lo tanto, fue conducido el estudio en obras y revistas bibliográficas, documentos puestos a disposición por la Municipalidad de São Bernardo do Campo (SBC) y noticias de periódicos archivados en el Memorial y Colección de la Ciudad. Para analizar el perfil de los usuarios, se realizaron entrevistas con 100 individuos elegidos al azar, durante los fines de semana de julio a septiembre 2012. El cambio en el paisaje debido a la formación de Billings, ha proporcionado su uso para el ocio y recreación. En la Prainha de Riacho Grande, datos sobre los flujos turísticos datan de 1970. La entrevista con los usuarios mostró que la mayoría eran jóvenes (29-39 años), ganando 1-2 salarios mínimos y de nivel de escolarización hasta la Escuela Secundaria. Originarios de la región metropolitana de São Paulo, principalmente de las ciudades de ABC. La mayoría afirmaba visitar el sitio con frecuencia acompañados por familiares o amigos, siempre a los fines de semana, para contemplar el paisaje y disfrutar de los productos vendidos allí. Los resultados corroboran otros estudios con usuarios de estas "prainhas" del Brasil, lo que demuestra la importancia de estos sitios como espacios de recreación para la población urbana de los alrededores, así como para la promoción del turismo como una alternativa para el desarrollo local y regional.
\end{abstract}

PALABRAS-CLAVE : ocio, recreación, turismo, represa. 


\section{INTRODUÇÃO}

O deslocamento de pessoas para lugares que não os seus habituais sempre aconteceu, seja pela busca de recursos como alimento e água, como também a procura de terras mais férteis e climas mais amenos, por motivos relacionados à sobrevivência ou ainda pelas peregrinações, devido às crenças religiosas (BRASIL, 2010).

Com o passar dos tempos, as formas de deslocamento, assim como as motivações para tal foram modificadas. As transformações na sociedade, decorrentes da Revolução Industrial propiciaram, além de melhores condições de viagem, mais tempo livre para ser usufruído com o lazer e assim, o turismo foi ganhando espaço no cenário mundial (DIAS, 2003).

A diminuição das horas de trabalho e o aumento do tempo livre despertou no homem, o desejo de preencher seu tempo com atividades associadas ao descanso, ao desenvolvimento e ao divertimento (CAMARGO, 2001; DUMAZEDIER, 2001). Nessa lógica Camargo (2001), salienta a necessidade de modificação dos espaços públicos para atender essa "nova" demanda da sociedade, o lazer.

O lazer pode ser entendido "... como a cultura, compreendida em seu sentido mais amplo, vivenciada no tempo disponível." (MARCELLINO, 2008, p. 13). $\mathrm{Na}$ intenção de dar subsídios para a compreensão do lazer, Dumazedier (1999) destaca seu caráter libertatório, como resultado de uma livre escolha e o caráter desinteressado, sem intenções lucrativas, profissionais, utilitárias ou ideológicas. Acrescenta ainda o caráter hedonistico, que evidencia a busca pelo estado de satisfação e o caráter pessoal, direcionado ao interesse e necessidade do próprio indivíduo. Entre as funções do lazer, considera-se o descanso, o divertimento e o desenvolvimento (DUMAZEDIER, 2001). A recreação situa-se como um componente do lazer (MARCELLINO, 2008).

Segundo Boullón (2002), a busca por lazer e recreação ao ar livre ou para consumir algum serviço recreativo da cidade atinge cerca de $20 \%$ da população urbana mundial. Mas espaços voltados a atender as necessidades recreativas da 
população, sobretudo as mais carentes, ainda são insuficientes na maioria das cidades.

As praias litorâneas são responsáveis por suprir boa parte da demanda por lazer e recreação nos municípios costeiros. Mas essa realidade é distinta nas demais cidades, principalmente, nos grandes aglomerados urbanos, pois os rios que as atravessam encontram-se, na maioria das vezes, em condições impróprias à recreação, devido à poluição de suas águas e margens por efluentes domésticos e industriais e por resíduos sólidos ou ainda por que tais ambientes aquáticos foram alterados drasticamente pela canalização (BOULLÓN, 2002).

No entanto, outra drástica modificação nos ecossistemas aquáticos vem favorecendo o aparecimento de áreas que têm sido aproveitadas para lazer, recreação e turismo. As inúmeras represas construídas no Brasil, com a finalidade de geração de energia elétrica vêm sendo exploradas para recreação e turismo (JULIO Jr. et al., 2005). No Estado de São Paulo, a transformação de três grandes rios (Tietê, Grande e Paranapanema) em uma sequência de reservatórios em "cascata" (HENRY et al., 2006; TUNDISI et al., 2002) alterou a geografia dessas bacias hidrográficas e resultou em novos ecossistemas e novas paisagens. Nesses "lagos construídos", surgiram praias que são aproveitadas para o desenvolvimento de atividades recreativas, que atraem tanto a população local quanto turistas.

Branco e Rocha (1977) também afirmam que os lagos artificiais proporcionam uma imagem nova e diferente à paisagem regional, que com o decorrer do tempo transformam-se em áreas de recreação. Nesses locais se estabelecem clubes náuticos, casas de veraneio e empreendimentos turísticos, que passam a compor as opções de lazer das populações. As represas Guarapiranga e Billings são exemplos de paisagens construídas que passaram a integrar o cenário urbano e a disponibilizar lazer à parte da população paulistana.

Deste modo, o presente estudo tem como objetivo discutir os usos múltiplos da Represa Billings, com enfoque na utilização para lazer, recreação e turismo. Além disso, pretende conhecer o perfil dos usuários da prainha do Riacho Grande, localizada nesta Represa com vista a compreender o que buscam e as atividades 
mais praticadas no local.

\section{ÁREA DE ESTUDO E MÉTODOS UTILIZADOS}

A Represa Billings localiza-se na Região Metropolitana de São Paulo e banha os municípios de Santo André, Diadema, Ribeirão Pires, São Paulo e São Bernardo do Campo, ocupando neste último uma área de 75,82 Km2 (SÃO BERNARDO DO CAMPO, 2012). Com a construção da Represa surgiram espaços propícios ao lazer e à recreação, envolvendo a prática de natação, esporte náuticos, pesca e contemplação da paisagem (FRACALANZA, 2002).

Entre esses espaços que apareceram com a formação do "lago" está a prainha do Riacho Grande, objeto de estudo desta pesquisa. Esta prainha localiza-se no bairro de Riacho Grande no município de São Bernardo do Campo, que tem uma população de 765.463 habitantes, segundo estimativas do IBGE (2011).

Para conhecer a história da Represa Billings e suas utilizações foi realizado levantamento bibliográfico em obras e periódicos que abordavam o assunto. Também foram consultados documentos disponibilizados pela Prefeitura Municipal de São Bernardo do Campo e notícias de jornais arquivadas no memorial e acervo da Cidade.

Para analisar o perfil dos frequentadores da prainha foram realizadas entrevistas com 100 indivíduos escolhidos aleatoriamente enquanto visitavam a área, durante finais de semana dos meses de julho, agosto e setembro de 2012. No total, quatro campanhas foram realizadas, cada uma com 25 abordagens.

A entrevista foi realizada por meio de um protocolo estruturado contendo 14 questões, 13 fechadas e uma aberta, que versavam sobre a faixa etária, gênero, origem e grau de escolaridade dos usuários e também perguntas relacionadas à frequência, tempo de permanência e atividades realizadas na Prainha.

\section{LAZER E TURISMO NA REPRESA BILLINGS}


Como a maioria das grandes represas brasileiras, a Billings foi construída com a finalidade de geração de energia hidrelétrica. Sua história se inicia com o aumento populacional na região metropolitana de São Paulo no início do século XX, quando a infraestrutura existente para atender a demanda de energia deixou de ser suficiente. Assim foi necessária a construção deste Reservatório para alimentar a Usina Hidrelétrica Henry Borden, em Cubatão (SP) (CARMO; TAGNIN, 2001).

Segundo os mesmos Autores, "o sistema hidráulico construído constituiu no represamento do Rio Grande (Jurubatuba) afluente do Rio Tietê, nas proximidades de Pedreira, em Santo Amaro, formando o reservatório Billings em 1927" (CARMO; TAGNIN, 2001, p.422).

Inicialmente construída para atender a demanda energética, outros usos foram logo incorporados a este corpo de água, como a pesca profissional e atividades relacionadas ao o lazer e a recreação, que datam da década de 1930. Tais usos foram decorrentes da mudança na paisagem pela formação da Represa Billings que propiciou sua utilização pela população do entorno para tais fins (ROCHA; MEICHES; LIMA-FILHO, 1986).

Neste período, a qualidade das águas do Reservatório possibilitava atividades que envolviam contato direto e indireto com as águas, como: natação; surf; esqui aquático; pesca; piquenique; e esportes a vela e a motor. Além disso, instalaram-se ao longo das margens do Reservatório alguns hotéis, clubes recreativos, colônias de férias e casas de veraneio. (FRACALANZA, 2002, p.08).

Rocha, Meiches e Lima-Filho (1986, p. 48) ressaltam que desde sua construção, a Billings foi considerada "um verdadeiro polo turístico e recreacional, sobretudo por estar situada em região próxima de áreas urbanas". Assim, a Represa passou a configurar uma opção de lazer de muitas famílias paulistanas aos finais de semana e períodos de férias. Tais afirmações são corroboradas por Branco e Rocha (1977). Além das atividades de lazer nas chamadas "prainhas", o entorno da Represa foi ocupado por loteamentos de chácaras recreativas e por clubes de campo, que se expandiram nas décadas de 1950 e 1960 (FRACALANZA, 2002). 
Ainda na década de 1960, a Billings acabou sendo requerida para resolver problemas referentes ao abastecimento populacional e industrial da região metropolitana de São Paulo. Este uso passou a ser conflitante com outros, como o controle das cheias dos rios Tietê e Pinheiros, proporcionado pela reversão das águas desses rios e a diluição de efluentes, que datam do final dos anos 50 (CARMO; TAGNIN, 2001; FRACALANZA, 2002).

Segundo, Rocha, Meiches e Lima-Filho (1986), a carga poluidora que chegava a Billings nesta época, devido ao bombeamento das águas desses rios, superava a capacidade de autodepuração da Represa, que podia ser comparada, em certos períodos, a uma lagoa de estabilização por suas características limnológicas.

Ações e programas governamentais, como os realizados pela Companhia Ambiental do Estado de São Paulo - CETESB, que datam da década de 1980 (ROCHA; MEICHES; LIMA-FILHO, 1986), o Programa de Recuperação Ambiental da Bacia da Billings (CARMO; TAGNIN, 2001), entre outros, foram insuficientes para reverter o quadro de poluição instalado. Estratégias como o controle da reversão e um sistema de flotação no rio Pinheiros parecem apenas minimizar as condições que comprometem os usos múltiplos da Represa, principalmente a utilização para lazer e recreação de contato primário (BRASIL, 2000) e o mais nobre dos usos, que é o abastecimento público (BRASIL, 1997).

Dados limnológicos de pesquisas recentes não são animadores e denunciam a grave degradação da qualidade das águas da Billings. A proliferação massiva de algas com potencial tóxico é cada vez mais frequente (OGASHAWARA; ZAVATTINI, TUNDISI, 2014; GEMELGO et al., 2008; CARVALHO et al., 2007; SANT'ANNA et al., 2007) e denuncia a elevada carga orgânica que chega à Represa. Outra preocupação é a existência de elevadas concentrações de metais pesados no sedimento e nos peixes, como mostram os estudos de Hortellani et al. (2013) e Oliveira (2012).

Em tempos de crise associada à escassez hídrica, a ausência de manejo adequado da Represa Billings soa no mínimo como um descaso e uma irresponsabilidade na gestão desse importante manancial, assim como demonstra um desrespeito à população que o utiliza e que dele poderia se beneficiar. 


\title{
A PRAINHA DO RIACHO GRANDE E O PERFIL DOS USUÁRIOS
}

Como visto, o fluxo de turista está presente na Represa Billings desde sua formação. Para a prainha do Riacho Grande, notícias da visitação foram encontradas numa matéria publicada em 1973 pelo Jornal Notícias do Município, arquivada no acervo da cidade de São Bernardo do Campo. A notícia relatava que além da pesca, principal divertimento da época, a Represa era procurada para esqui e passeios de barco, como passatempo do público jovem no distrito do Riacho Grande.

A presença de visitantes na prainha do Riacho Grande foi comentada em 1981, pelo subprefeito do Riacho Grande, Ronald Bellinghousen, enquanto eram realizadas as obras que originariam a Prainha:

\begin{abstract}
Os espaços à beira da represa sempre existiram e precisavam ser aproveitados. Então tivemos a ideia e demos inicio aos trabalhos, cortando o mato, aterrando brejos, limpando tudo através de Administração Direta, o que barateou os custos. A medida que os trechos de praias são concluídos eles vão sendo liberados ao público. E o grande comparecimento de pescadores e turistas aos trechos prontos tem nos incentivado a continuar, desenvolvendo outras idéias (NOVAS PRAIAS E FEIRA DO ARTESANATO NO RIACHO GRANDE, 1981, s/p).
\end{abstract}

Os resultados dessa pesquisa revelaram que a maioria dos frequentadores entrevistados na Prainha (39\%) tem entre 29 e 39 anos. A faixa etária predominante assemelha-se ao público da Represa do Lobo (Bairro do Broa), no Município de Itirapina, SP, que em 2002 constatou como dominante os usuários entre 25 e 35 anos (MATHEUS; MORAES; CAFFAGNI, 2005). A diferença entre homens e mulheres presentes no local é pequena, o público feminino representa $51 \%$ e o masculino $49 \%$.

A pesquisa mostrou que $33 \%$ dos frequentadores vêm da região metropolitana de São Paulo. Destes, $67 \%$ são do Grande $A B C$, região que mais emite "turistas" para a prainha do Riacho Grande. O município de São Bernardo onde está localizada a Prainha é responsável por $52,24 \%$ dos usuários, porém os moradores locais do bairro Riacho Grande aparecem em pequena quantidade, sendo somente $6 \%$ dos usuários. Ao contrário do que ocorre no Parque Ecológico Guarapiranga, a 
maior incidência de usuários é advinda do bairro Jd. Rivieira, onde está localizado o parque (PEREIRA; LIPPI, 2009).

O fato de moradores locais não serem a maioria dos frequentadores da praia pode estar relacionado ao que foi dito pelo subprefeito do Riacho Grande Henrique Vidal no ano de 1999, em entrevista ao diário do grande ABC "a comunidade sempre reclamou do barulho, da bagunça e da sujeira nos fins de semana" (RIACHO GRANDE, 1999, s/p). O aborrecimento pode ser causado pelo grande e descontrolado fluxo que acontece no local, atrapalhando o dia a dia dos moradores, como o aumento de transito, poluição e barulho, problemas causados pela falta planejamento, citado por Dias (2003):

Problemas gerados pela saturação da infraestrutura: a vida diária dos residentes nos destinos turísticos pode sofrer impactos sérios devido ao uso das instalações e recursos existentes pelos visitantes, aumentando a rejeição e a irritabilidade da população local em relação aos turistas (Dias, 2003, p.30).

O grau de escolaridade predominante entre os entrevistados desta pesquisa é de pessoas que concluíram os estudos até o ensino médio (31\%), seguido dos que não concluíram o ensino médio (20\%). Na represa do Lobo (Broa), o maior público é o de pessoas com nível superior completo (25\%), seguido daquele com baixa escolaridade, que concluíram os estudos até o $1^{\circ} \mathrm{grau}$ incompleto (23\%) (MATHEUS; MORAES; CAFFAGNI, 2005). Já no Complexo da Cachoeira da Fumaça, localizado em Carrancas, Minas Gerais, Andretta et al (2008) observaram que 48\% dos entrevistados cursavam ou concluíram o curso superior e relacionaram o nível de escolaridade a uma boa receptividade em relação a esclarecimentos quanto às questões ambientais e sua conservação, como observado em outras questões no estudo. A baixa escolaridade pode estar associada ainda à renda mensal. Neste estudo, aproximadamente $66 \%$ dos participantes declararam receber de 1 a 2 salários mínimos ao mês e $23 \%$, de 3 a 4 .

A maioria dos entrevistados declarou visitar a prainha do Riacho Grande com certa constância, pois $55 \%$ afirmaram já ter frequentado o local por mais de dez 
vezes, enquanto $9 \%$ estavam visitando pela primeira vez. Já no estudo realizado no complexo da cachoeira da fumaça, 63,6\% afirmaram estar conhecendo o local pela primeira vez, como relatado por Andretta et al (2008).

A prainha do Riacho Grande apresenta-se como ambiente familiar, onde a maioria dos visitantes vão acompanhados de família/amigos. Este fato também foi observado na cachoeira da fumaça (Carrancas, MG) (ANDRETTA, 2008), na represa do Lobo (Itirapina, SP) (MATHEUS; MORAES; CAFFAGNI, 2005), e no Parque Ecológico Guarapiranga (São Paulo, SP) (PEREIRA; LIPPI, 2009).

A facilidade proporcionada pela proximidade das rodovias foi o motivo atribuído por Andretta et al (2008) para justificar os cerca de $87 \%$ visitantes da cachoeira da fumaça, que se utilizam dos carros como o principal meio de transporte para o local. Nesta pesquisa, o carro foi apontado por $82 \%$ dos entrevistados como principal meio de transporte para chegar a Prainha do Riacho Grande, que se localiza próxima a Rodovia Anchieta, via de fácil acesso a população paulistana que liga a região metropolitana ao litoral.

De acordo com o observado durante a aplicação da pesquisa, a maioria dos visitantes da Prainha estudada alega visitar o local a passeio aos finais de semana, assim como ocorre no Parque Guarapiranga, que é utilizado como forma de entretenimento para a família, principalmente aos sábados e domingos (PEREIRA; LIPPI, 2009); o mesmo foi observado por Dias e Granado (No prelo), nas prainhas do Município de Rosana (SP).

A principal atividade realizada na Prainha do Riacho Grande apontada pelos participantes desta pesquisa foi o passeio para contemplar a paisagem (64\%). E apesar da constatação de elevada incidência de pessoas nas águas da represa, durante as observações in loco, o banho na Represa Billings foi a atividade citada por $16 \%$ dos entrevistados.

Um estudo realizado por Leme (2007), na Represa Jaguari-Jacareí, considerada um importante atrativo turístico na região de Bragança Paulista (SP), também constatou que a contemplação da paisagem foi a atividade apontada como a mais praticada pelos frequentadores do entorno deste corpo de água. 
Contudo, em geral, atividades de contato primário como o banho e a natação estão entre as atividades mais realizadas por frequentadores de prainhas de água doce (ANA, 2005; ANDRETTA et al., 2008; DIAS; GRANADO, No prelo). A garantia de qualidade ambiental em ecossistemas aquáticos usados para recreação é fundamental para que a atividade não cause prejuízos à saúde dos usuários, principalmente, no caso da recreação de contato primário, em que há contato direto e prolongado com a água e a possibilidade de ingestão (BRASIL, 2000).

A Resolução do Conselho Nacional de Meio Ambiente - CONAMA №. 274, de 29 de novembro de 2000 trata especificamente das condições de balneabilidade, estabelecendo padrões de qualidade ambiental, que classificam as águas como próprias ou impróprias à recreação de contato primário. Esta Resolução tem o estado bacteriológico dos ambientes aquáticos como a principal variável considerada para verificação da qualidade das águas destinadas ao lazer e à recreação de contato primário (banho, natação, mergulho), tanto para praias costeiras, quanto de águas interiores. Indicadores da presença de material fecal, denominados coliformes fecais, incluindo a bactéria Escherichia coli, são usados para classificar ambientes aquáticos como adequados ou não a balneabilidade(Brasil, 2000).

Neste contexto, para este estudo, $61 \%$ dos entrevistados disseram acreditar que água da Billings é imprópria para banho. Dentre os $39 \%$ que consideravam a água adequada para este fim, alguns alegaram que se a água fosse poluída haveria algum tipo de sinalização no local informando sobre essa proibição, como acontece no litoral paulista, onde as praias são sinalizadas como impróprias por bandeiras vermelhas e as praias próprias sinalizadas com bandeiras verdes pela Companhia de Tecnologia de Saneamento Ambiental - CETESB.

Estes resultados vão de encontro aos obtidos no estudo do complexo da cachoeira da fumaça, em que $61 \%$ dos visitantes do local alegaram não se banhar, por acreditarem que a água esteja poluída (ANDRETTA et al., 2008).

Para a Prainha do Riacho Grande, os resultados do índice de balneabilidade divulgados pela CETESB demostram que a qualidade da água esteve imprópria na maioria das semanas do ano de 2012, principalmente durante o verão quando a 
visitação é mais intensa e o local é mais utilizado para banho.

Dessa forma, percebe-se a incompatibilidade entre os diferentes usos da água na Represa Billings, já que o bombeamento dos rios Tietê e Pinheiros, num primeiro momento para atender a geração hidrelétrica e em seguida, como forma de atenuar os problemas de inundação da capital paulista e a diluição de efluentes domésticos e industriais comprometem seu uso para a recreação de contato primário e até para o abastecimento público, agravando a escassez hídrica da região (WENGRAT; BICUDO, 2011).

Ainda assim, a represa Billings é considerada um importante espaço de lazer da Região Metropolitana de São Paulo (BRANCO; ROCHA, 1977) e o principal atrativo do bairro Riacho Grande para $52 \%$ dos entrevistados. Um projeto de revitalização da Prainha de Riacho Grande estava sendo iniciado durante o desenvolvimento desta pesquisa e, de acordo com a Prefeitura Municipal de São Bernardo do Campo (2012), o objetivo é readequar o espaço com infraestrutura que atenda os usos para contemplação e para prática esportes náuticos, que envolvam a recreação de contato secundário, cujo padrão de qualidade da água é menos restritivo (BRASIL, 2005).

\section{CONSIDERAÇÕES FINAIS}

A mudança na paisagem pela formação da Represa Billings propiciou sua utilização para fins de lazer e recreação. Na prainha do Riacho Grande em São Bernardo do Campo, notícias do fluxo de turistas datam da década de 1970. Apesar da comprometida qualidade da água e do insucesso dos programas de recuperação realizados no corpo de água, os resultados deste trabalho demonstram a importância da Represa como espaço de lazer associado à paisagem urbana na Região Metropolitana de São Paulo. E ainda que suas águas não permitam o uso para recreação de contato primário, devido aos conflitos de usos existentes, os resultados obtidos evidenciam a Prainha de Riacho Grande como atrativo turístico e espaço de lazer destinado às populações urbanas, assim como para a promoção do turismo 
como alternativa de desenvolvimento local e regional, corroborando com outros estudos em prainhas no Brasil.

\section{AGRADECIMENTOS}

As autoras agradecem a Prefeitura Municipal de São Bernardo do Campo por disponibilização do acervo histórico municipal, e aos usuários da Prainha do Riacho Grande que responderam a pesquisa.

\section{REFERÊNCIAS}

AGÊNCIA NACIONAL DAS ÁGUAS - ANA. Caderno de Recursos Hídricos: o turismo e o lazer e sua interface com o setor de recursos hídricos. Brasília, 2005. Disponível em:

(http://www.ana.gov.br/ nrh_novo/documentos/06\%20Turismo/VF\%20Turismo\%20Lazer.pdf. Acesso em: 20 de março de 2011.

ANDRETTA, V.; PEREIRA, J. A. A.; MACEDO, R. L. G.; LOPES, F. W. A.; VITORINO, M. R. Impactos ambientais e perfil dos visitantes no Complexo da Cachoeira da Fumaça em Carrancas/MG. Caderno Virtual de Turismo, v. 8, p. 57-68, 2008.

BOULLÓN, RC. Atividades turísticas e recreativas: o homem como protagonista. EDUSC, Bauru, SP. 2004. 208 p.

BRASIL. Lei N. 9433, de 8 de janeiro de 1997. Institui a Política Nacional de Recursos Hídricos, cria o Sistema Nacional de Gerenciamento de Recursos Hídricos, regulamenta o inciso XIX do art. 21 da Constituição Federal, e altera o art. $1^{\circ}$ da Lei $n^{\circ} 8.001$, de 13 de março de 1990, que modificou a Lei $n^{\circ}$ 7.990, de 28 de dezembro de 1989. Disponível em: www.planalto.gov.br. Acesso em: 30 de maio de 2010.

BRASIL. CONAMA. CONSELHO NACIONAL DE MEIO AMBIENTE. Resolução N. 274, de 29 de novembro de 2000. Dispõe sobre a balneabilidade dos corpos de água e dá outras providências. Disponível em: www.planalto.gov.br. Acesso em: maio de 2010.

BRASIL. CONAMA. CONSELHO NACIONAL DE MEIO AMBIENTE. Resolução N. 357, de 17 de março de 2005. Dispõe sobre a classificação dos corpos de água e diretrizes ambientais para o seu enquadramento, bem como estabelece as condições e padrões de lançamento de efluentes, e dá outras providências. Disponível em: www.planalto.gov.br. Acesso em: abril de 2011.

BRASIL. Ministério do Turismo. Dados do turismo brasileiro. 2010. Disponível em: http://www.turismo.gov.br/export/sites/default/turismo/o ministerio/publicacoes/downloads publicacoes/ Cartilha-Dados Turismo-15x21-web.pdf. Acesso em: 02 de outubro de 2013.

BRANCO, S. M.; ROCHA, A. A. Poluição, proteção e usos múltiplos de represas. São Paulo: Edgard Blucher, Cetesb, 1977.

CAMARGO, LOL. Educação para o lazer. $3^{\text {a }}$ Ed. Coleção Polêmica. , São Paulo: Moderna. 2001. $160 p$. 
CARMO, R. L.; TAGNIN, R. Uso múltiplo da água e múltiplos conflitos em contextos urbanos: o caso do Reservatório Billings, Anais do IX Encontro Nacional da Associação Nacional de Pós-Graduação e Pesquisa em Planejamento Urbano e Regional (ANPUR). Rio de Janeiro, RJ, BRASIL, p. 421-439, 2001.

CARVALHO, L. R.; SANT' ANNA, C. L.; GELMEGO, M. C. P; AZEVEDO, M. T. P. Cyanobacterial ocurrence and detection of microcystin by planar chromatography in surface water of Billings and Guarapiranga Reservoirs, SP, Brazil. Revista Brasileira de Botânica. v. 30, p. 141-148, jan-mar., 2007.

CETESB. Classificação semanal de praias em rios e reservatórios -2012: Represas. Disponível em: <http://www.cetesb.sp.gov.br/qualidade-das-represas>. Acesso em: 26 out. 2012.

DIAS, Reinaldo. Planejamento do Turismo : política e desenvolvimento do turismo no Brasil. São Paulo: Editora Atlas, 2003. 205 p.

DIAS, G. M.; GRANADO, D. C. Lazer e recreação associados aos ambientes aquáticos numa pequena cidade do interior paulista. Colloquium Humanarum, No prelo.

DUMAZEDIER, J. Lazer e cultura popular. $3^{\mathrm{a}}$ Ed. Debates, 82. Perspectiva, São Paulo. 2001, 333p. . Sociologia empírica do lazer. 2.ed. São Paulo: Perspectiva. 1999.

FRACALANZA, A. P. Reservatório Billings: apropriação da água, conflitos e gestão. Anais do Encontro da Associação Nacional de Pós Graduação e Pesquisa em Ambiente e Sociedade, Indaiatuba. 2002. p. 1 - 16. Disponível em:

<http://www.anppas.org.br/encontro_anual/encontro1/gt/recursos_hidricos/ANA\%20PAULA\%20FRACA LANZA.pdf $>$. Acesso em: 06 junh. 2012.

GELMEGO, M. C; SANT' ANNA, C. L.; TUCCI, A.; BARBOSA, H. R. Dinâmica populacional de Cylindrospermopsis raciborskii (Woloszinska) Seenaya \& Subba raju, uma espécie tóxica de cianobactéria em reservatórios de abastecimento, SP, Brasil. Hoehnea, v. 35, n. 2, p. 297-307, 2008.

HENRY, R., PANARELLI, EA., CASANOVA, SMC., SUIBERTO, MR. \& AFONSO, AAO. Interações hidrológicas entre lagoas marginais e o rio Paranapanema na zona de sua desembocadura na Represa de Jurumirim. In: NOGUEIRA, MG, JORCIN, A. \& HENRY, R. (Eds). Ecologia de reservatórios: impactos potenciais, ações de manejo e sistemas em cascata. $2^{\mathrm{a}}$ Ed. Rima, São Carlos. 2006, p.56-82.

HORTELLANI, M. A.; SARKIS, J. E. S.; MENEZES, L. C. B.; YAMAGUISHI, R. B.; PEREIRA, A. S. A.; GARCIA, P. F. G.; MARUYAMA, L. S.; CASTRO, P. M. G. Assessment of metal concentration in the Billings Reservoir, São Paulo State, Southeastern Brazil. Journal of the Brazilian Chemical Society, v. 24, p. 58-67, jan. 2013.

INSTITUTO BRASILEIRO DE GEOGRAFIA E ESTATÍSTICA - IBGE. IBGE divulga as estimativas populacionais dos municípios em 2011. Disponível em:

<http://www.ibge.gov.br/home/presidencia/noticias/noticia_visualiza.php?id_noticia=1961\&id_pagina=1 >. Acesso em: 08 jul. 2012.

JULIO Jr., HF., THOMAZ, SM., AGOSTINHO, AA. \& LATINI, JD. Distribuição e caracterização dos reservatórios. In: RODRIGUES, L., THOMAZ, SM., AGOSTINHO, AA. \& GOMES, LC. (Org.).

Biocenoses em reservatórios: padrões espaciais e temporais. São Carlos: Rima, São Carlos. 2005. p. 1-16. 
LEME, F. B. M. Represas como territórios, lugares e paisagens: subsídios para o planejamento turístico sustentável. 2007. 214f. Dissertação (Mestre em Ciências Sociais) - Universidade Estadual De Santa Cruz, Ilheús, 2007.

MARCELLINO, N. C. Lazer e sociedade: múltiplas relações. Campinas, SP: Alínea, 2008.

MATHEUS, C. E.; MORAES, A. J.; CAFFAGNI, C. W. A. Educação ambiental para o turismo sustentável. São Carlos: Rima, 2005. 180 p.

NOVAS PRAIAS E FEIRA DO ARTESANATO NO RIACHO GRANDE. Jornal Noticias do Municipio, São Bernardo do Campo, SP, 02 de maio de 1981.

OGASHAWARA, I.; ZAVATTINI, J. A.; TUNDISI, J. G. The climatic rhythm and blooms of cyanobacteria in a tropical reservoir in São Paulo, Brazil. Brazilian Journal Biology, v. 74, p. 72-78, 2014. OLIVEIRA, T. A. Metais presentes nas águas e em tecidos de peixes da Represa Billings: uma avaliação temporal. 2012. 215 f. Dissertação. Instituto de Pesquisas Energéticas e Nucleares, Universidade de São Paulo, 2012.

PEREIRA, M. C. G.; LIPPI, M. S. S. P. Análise do perfil socioambiental dos usuários do Parque Ecológico Guarapiranga, São Paulo. $1^{\circ}$ Congresso de Iniciação Científica e $6^{\text {a }}$ Mostra de PósGraduação. Universidade de Santo Amaro - UNISA, 2009. Disponível em : http://www.unisa.br/pesquisa/arquivos/livro 12 congresso.pdf\#page=86. Acesso em: abril de 2014 .

RIACHO GRANDE FAZ MULTIRÃO PARA MELHOR RECEBER TURISTA. Diário do Grande ABC, São Bernardo do Campo, SP, 21 de junho de 1999.

ROCHA, A. A.; MEICHES, L. A. M.; LIMA FILHO, R. A. L. A qualidade sanitária e a represa Billings. Revista DAE, v. 46, n. 144, p. 48-51, mar. 1986.

SANT' ANNA, C. L.; MELCHER, S. S.; CARVALHO, L. R.; GELMEGO, M. C. P; AZEVEDO, M. T. P. Planktic cyanobacteria from upper Tietê basin reservoir, SP, Brazil. Revista Brasileira de Botânica. v. 30, p. 1-17, jan-mar., 2007.

SÃO BERNARDO DO CAMPO. Geografia e Meio Ambiente- Represa Billings. Disponível em:<http://www.saobernardo.sp.gov.br/comuns2/pqt_container_novo2.asp?srcpg=sdet\&area=SDET\&ti po=A\%20Secretaria\&unidade=GSDET>. Acessado em 23 de ago. 2012.

TUNDISI, JG, MATSUMURA-TUNDISI, T. \& ROCHA, O. Ecossistemas de águas interiores. In: REBOUÇAS, AC., BRAGA, B. \& TUNIDISI, JG. (Orgs). Águas doces no Brasil. $2^{a}$ Ed. Escrituras, São Paulo. 2002. p.153-194.

WENGRAT, S.; BICUDO, D. C. Spatial evaluation of water quality in na urban reservoir (Billings Complex, southeastern Brazil). Acta Limnologica Brasiliensia, v. 23, n. 2, p. 200-216, 2011. 